\title{
Preventing Foodborne Illness: Listeriosis ${ }^{1}$
}

\section{Keith R. Schneider, Renée Goodrich-Schneider, Michael A. Hubbard, and Susanna Richardson²}

This is one in a series of fact sheets discussing common foodborne pathogens of interest to food handlers, processors, and retailers.

\section{What causes a Listeria-associated foodborne illness?}

Listeria monocytogenes is the bacterium that causes the foodborne disease listeriosis. Listeriosis is classified as a foodborne infection and is one of several foodborne diseases that are often reported in the scientific and popular press. Listeriosis expresses itself in the affected person by means of septicemia, meningitis (or meningoencephalitis), and/or encephalitis (Murray et al. 2007). Pregnant women who have intrauterine or cervical infections caused by $L$. monocytogenes in their second or third trimesters may spontaneously abort the fetus or produce a stillbirth (Murray et al. 2007). Influenza-type symptoms, which may include continuous fever, usually precede the aforementioned disorders. In the United States, listeriosis affects about 1,600 people every year, with about 270 of those cases resulting in death (Scallan et al. 2011).

\section{Outbreaks associated with Listeria monocytogenes}

The largest recent outbreak of L. monocytogenes occurred during the fall of 2011 and was caused by cantaloupes grown in Colorado. This outbreak sickened 147 people, most of them over the age of 60. Ninety-nine percent of the people affected were hospitalized, and 33 people died. By the end of the outbreak, 28 states having at least one person with this particular group of L. monocytogenes strains had been identified (CDC 2011).

Listeria was also found in Mexican soft cheese during the fall of 2000 in Winston-Salem, North Carolina, among the Hispanic population. In this outbreak, 12 people became ill, most of them women and several of them pregnant, resulting in five stillbirths, three premature deliveries, and two infected newborns. The implicated cheese was purchased from door-to-door vendors and is believed to have become contaminated with $L$. monocytogenes from environmental contaminants. This outbreak prompted North Carolina to prohibit dairies from selling raw milk. The state also began educating food vendors about the dangers of selling dairy products made with unpasteurized milk (CDC 2001).

Ready-to-eat (RTE) foods, such as luncheon meat, hot dogs, and precooked sliced meat, are also highly susceptible to L. monocytogenes contamination. In 2002, there was an outbreak of L. monocytogenes from sliced delicatessen turkey meat, when 54 people were infected and eight fatal infections and three fetal deaths occurred. The follow-up investigation found the processing plant was the source of infection. Approximately 30 million pounds of poultry product were recalled from these processing plants. This outbreak led to multiple changes in FDA policy regarding the inspection and handling of RTE foods, particularly

1. This document is FSHN03-6, one of a series of the Food Science and Human Nutrition Department, Florida Cooperative Extension Service, Institute of Food and Agricultural Sciences, University of Florida. Original publication date June 2003. Revised March 2013. Visit the EDIS website at http://edis.ifas. ufl.edu.

2. K.R. Schneider, Ph.D., associate professor; R. Goodrich-Schneider, Ph.D., associate professor; M.A. Hubbard, laboratory technician; and S. Richardson, laboratory technician, Food Science and Human Nutrition Department, Cooperative Extension Service, Institute of Food and Agricultural Sciences, University of Florida, Gainesville 32611D. 
those that are poultry based (Gottlieb et al. 2006; Olsen et al. 2005).

One of the worst L. monocytogenes outbreaks involved hot dogs served in North Carolina in 2000. More than 100 people showed symptoms and 21 died (Evans et al. 2004). There is still some confusion about exactly how the hot dogs became contaminated. The theory that this was a specialized heat-resistant strain of L. monocytogenes was suggested as the reason normal sanitation processes failed. However, after extensively testing the strain that caused this outbreak, it was determined that it was only slightly different and had no specific heat-resistant properties when compared to the L. monocytogenes strain typically implicated in other outbreaks (Mazzotta and Gombas 2001).

Raw milk, improperly pasteurized fluid milk, raw vegetables, fermented raw-meat sausages, and raw and cooked poultry have all been associated with $L$. monocytogenes. Other foods that may contain L. monocytogenes include RTE seafood (e.g., smoked fish and smoked mussels), premixed raw vegetable salads like coleslaw, precooked meat products eaten without further cooking (e.g., pâtés, sliced deli meat, and cooked diced chicken [as used in sandwich shops]), soft-serve ice creams, and soft cheeses, such as traditional Mexican cheeses, Camembert, and ricotta (CDC 2012).

\section{What type of bacterium is Listeria?}

Listeria monocytogenes is a small, Gram-positive, nonspore-forming, rod-shaped bacterium that uses flagella for movement (Murray et al. 2007). L. monocytogenes can grow in a variety of growth conditions: temperatures ranging from $37^{\circ} \mathrm{F}$ to $104^{\circ} \mathrm{F}$ and a $\mathrm{pH}$ range from 4.4 to 9.6 (Milillo et al. 2012). The ability of this organism to grow at refrigeration temperatures and withstand slightly acidic conditions (commonly found in some cheeses) makes controlling it difficult. Some research suggests large doses of Listeria can survive heat treatments of $160^{\circ} \mathrm{F}$ (Mazzotta and Gombas 2001). Despite the small number of cases reported each year, Listeria remains a major health concern in food and is gaining more public recognition because of its high mortality rate.

Some studies have shown that $L$. monocytogenes can be in the intestines of $1 \%-10 \%$ of humans (Farber and Peterkin 1991; Ramaswamy et al. 2007). L. monocytogenes has also been found in many species of birds, domestic and feral mammals, and in some species of fish and shellfish (Farber and Peterkin 1991). L. monocytogenes is quite hardy and can survive long periods in food processing environments, especially around moist areas such as drains and air conditioning vents that develop condensate (Blackman and Frank 1996). Although it does not form spores, it is somewhat resistant to the deleterious effects of freezing, drying, and heat.

\section{How is the Listeria bacterium spread?}

Listeria is widely found in nature in places such as water, soil, contaminated animals, human and animal feces, raw and treated sewage, effluent from poultry and meat processing facilities, decaying corn and soybeans, improperly fermented silage, and normal and mastitic milk prior to pasteurization (Farber and Peterkin 1991; Ramaswamy et al. 2007). It is mainly transmitted to humans through food. Other, though rare, means of transmission are plant to human (not from ingestion), animal to human, air to human, and human to human (Ramaswamy et al. 2007).

Infants can acquire L. monocytogenes by mother-to-fetus transmission when the fetus is still in the womb or directly from their mothers at the time of birth (Ramaswamy et al. 2007). Direct contact with L. monocytogenes can cause lesions on the hands or arms and has, in rare cases, been transmitted during sexual contact (Ramaswamy et al. 2007). Inhalation of L. monocytogenes is another route of infection, although this is atypical.

L. monocytogenes can inhabit animal intestines without causing sickness (Ramaswamy et al. 2007). Since the animal would show no signs of any illness, L. monocytogenes could spread to meat and dairy products without the producer's knowledge. The organism is killed by cooking or other heating methods such as pasteurization, processes commonly used to produce RTE foods; however, it should be noted that RTE foods may become contaminated after the final heat treatment (Ramaswamy et al. 2007).

\section{Symptoms of listeriosis}

Listeriosis is identified when L. monocytogenes is detected in blood, cerebrospinal fluid, the placenta or fetus, and other such normally sterile areas in the body (Ramaswamy et al. 2007).

In mild cases of listeriosis that typically occur in otherwise healthy people, gastrointestinal symptoms may be the only symptoms (Ramaswamy et al. 2007). The time from the initial symptoms to manifestation of serious illness is not known, but it is probably a few days to three weeks. Listeriosis in the affected person commonly produces fever, 
muscle aches, and flu-like symptoms. Headache, stiff neck, confusion, loss of balance, or convulsions may result if the bacteria invade the nervous system (CDC 2012).

\section{High-risk populations for listeriosis}

L. monocytogenes can affect people differently. Healthy people may have few or no symptoms, while others might suffer a serious, life-threatening infection that could require hospitalization or might even result in death.

High-risk groups for listeriosis include the following:

- Pregnant women

- Newborn babies

- Persons with weakened immune systems as a result of disease or illness, such as

- cancer;

- leukemia;

- diabetes;

- liver or kidney disease;

- HIV / AIDS (It has been estimated that persons suffering from AIDS are about 200-300 times more likely to be affected by listeriosis.);

- autoimmune disease (e.g., lupus);

- persons using prednisone or cortisone medication, as these can also suppress the immune system;

- organ transplant patients; and

- the elderly (CDC 2012; Ramaswamy et al. 2007).

\section{Sanitation methods for} minimizing the risk of listerisos in the plant or food establishment

\section{Clean}

Use hot, soapy water and a sanitizer to wash hands and food-contact surfaces often. Wash hands, cutting boards, dishes, and utensils after they come in contact with raw food. Clean liquid spills in the refrigerator, especially spills from products associated with L. monocytogenes, such as luncheon meats and hot dogs. L. monocytogenes can grow slowly in the refrigerator and can easily spread to previously uncontaminated areas through contact with containers, packages, and other food items.
- Ensure employees wash hands before, during, and after handling any food, particularly raw meat and poultry.

- Sanitize all utensils, cutting boards, and work surfaces with an approved sanitizing agent before and after use.

- Clean food contact surfaces such as refrigerator shelving if they come in contact with possible sources of $L$. monocytogenes contamination (i.e., purge from open packages of luncheon meats or hot dogs).

\section{Separate}

Treat all RTE foods, raw meat, poultry, and seafood as possible sources of contamination. Keep these types of foods separate from items that are not traditionally cooked or potentially can be eaten raw, such as vegetables, fruits, breads, and other already prepared, edible foods. This reduces the chance of cross-contamination.

- The utensils used for raw and cooked foods should be separate.

- Meats and other potential sources of contamination should be stored in places that rest below storage areas for foods that may be consumed raw.

- Rewrap open packages carefully or store in leak-proof containers to prevent cross-contamination.

\section{Cook}

Heat foods to safe temperatures. People who are in the high-risk groups for listeriosis should cook, until steaming hot $\left(165^{\circ} \mathrm{F}\right)$, all luncheon meats, cold cuts, other deli-style meats, and poultry (FSIS 1999; Ramaswamy et al. 2007).

The 2009 FDA Food Code recommends cooking most potentially hazardous foods to an internal temperature of $165^{\circ} \mathrm{F}$ or above for 15 seconds (refer to Sections 3-4: Destruction of Organisms of Public Health Concern, Subparts 3-401 and 3-501 of the 2009 FDA Food Code for specific details on cooking temperatures)(FDA 2009).

Freezing or refrigeration will not kill L. monocytogenes; it can grow and multiply in refrigerated storage. At the present time, proper cooking and personal hygiene, good sanitation, and preventing cross-contamination of raw and cooked food are the best measures to control Listeria. Recommendations to reduce the incidence of foodborne listeriosis include the following: 
- Don't store food in the temperature danger zone between $39.2^{\circ} \mathrm{F}$ and $140^{\circ} \mathrm{F}$. The refrigerator should be at $39.2^{\circ} \mathrm{F}$ or colder. All food should be refrigerated promptly.

- Completely cook or boil foods like hot dogs and poultry products until they become steaming hot.

- Don't consume raw, unpasteurized milk or its derived foods, like raw milk cheese.

\section{Storage}

Try to limit room temperature exposure of food to two hours or less before returning perishables and RTE foods to the refrigerator or freezer.

- Cover all food to prevent cross-contamination.

- Place all cooked food in the refrigerator within one hour of cooking.

- Place uncooked meat, poultry, fish, or other raw products below cooked or RTE foods in the refrigerator to prevent cross-contamination.

- Maintain the refrigerator temperature at or below $4^{\circ} \mathrm{C}$ and keep the refrigerator clean.

- Observe strictly the "use by" or "best by" dates on refrigerated items (FSIS 1999).

\section{References}

Blackman, I. C., and J. F. Frank. 1996. "Growth of Listeria monocytogenes as a Biofilm on Various Food-Processing Surfaces." Journal of Food Protection 59 (8): 827-831.

CDC (Centers for Disease Control and Prevention). 2001. "Outbreak of Listeriosis Associated with Homemade Mexican-Style Cheese: North Carolina, October 2000January 2001." Morbidity and Mortality Weekly Report 50 (26): 560-562.

CDC (Centers for Disease Control and Prevention). 2011. "Investigation Update: Multistate Outbreak of Listeriosis Linked to Whole Cantaloupes from Jensen Farms, Colorado." Accessed August 27, 2012. http://www.cdc.gov/ listeria/outbreaks/cantaloupes-jensen-farms/092711/index. html.

CDC (Centers for Disease Control and Prevention). 2012. "Listeriosis." National Center for Emerging and Zoonotic Infectious Diseases. Division of Foodborne, Waterborne, and Environmental Diseases. Accessed November 21, 2012. http://www.cdc.gov/listeria/.

Evans, M. R., B. Swaminathan, L. M. Graves, E. Altermann, T. R. Klaenhammer, R. C. Fink, S. Kernodle, and S.
Kathariou. 2004. "Genetic Markers Unique to Listeria monocytogenes Serotype 4b Differentiate Epidemic Clone II (Hot Dog Outbreak Strains) from Other Lineages." Applied and Environmental Microbiology 70 (4): 2383-2390.

Farber, J. M., and P. I. Peterkin. 1991. "Listeria monocytogenes, a food-borne Pathogen." Microbiological Reviews 55 (3): 476-511.

FDA (U.S. Food and Drug Administration). 2009. "FDA 2009 Food Code - Table of Contents." http://www.fda. gov/Food/FoodSafety/RetailFoodProtection/FoodCode/ FoodCode2009/default.htm.

FSIS (Food Safety and Inspection Service). May 1999. "Listeria Guidelines for Industry." http://www.fsis.usda.gov/ OA/topics/lmguide.htm.

Gottlieb, S. L., E. C. Newbern, P. M. Griffin, L. M. Graves, R. M. Hoekstra, N. L. Baker, S. B. Hunter, K. G. Holt, F. Ramsey, M. Head, P. Levine, G. Johnson, D. SchoonmakerBopp, V. Reddy, L. Kornstein, M. Gerwel, J. Nsubuga, L. Edwards, S. Stonecipher, S. Hurd, D. Austin, M. A. Jefferson, S. D. Young, K. Hise, E. D. Chernak, J. Sobel, and the Listeriosis Outbreak Working Group. 2006. "Multistate Outbreak of Listeriosis Linked to Turkey Deli Meat and Subsequent Changes in US Regulatory Policy." Clinical Infectious Diseases 42 (1): 29-36.

Mazzotta, A. S., and D. E. Gombas. 2001. "Heat Resistance of an Outbreak Strain of Listeria monotcytogenes in Hot Dog Batter." Journal of Food Protection 64 (3): 321-324.

Milillo, S. R., E. C. Friedly, J. C. Saldivar, A. Mythaiyan, C. O'Bryan, P. G. Crandall, M. G. Johnson, and S. C. Ricke. 2012. "A Review of the Ecology, Genomics, and Stress Response of Listeria innocua and Listeria monocytogenes." Critical Reviews in Food Science and Nutrition 52 (8): 712-725.

Murray, P. R., E. J. Baron, J. H. Jorgensen, M. L. Landry, and M. A. Pfaller, eds. 2007. Manual of Clinical Microbiology (9th ed.). Washington, D.C.: ASM Press.

Olsen, S. J., M. Patrick, S. B. Hunter, V. Reddy, L. Kornstein, W. R. MacKenzie, K. Lane, S. Bidol, G. A. Stoltman, D. M. Frye, I. Lee, S. Hurd, T. F. Jones, T. N. LaPorte, W. Dewitt, L. Graves, M. Weidmann, D. J. Schoonmaker-Bopp, A. J. Huang, C. Vincent, A. Bugenhagen, J. Corby, E. R. Carloni, M. E. Holcomb, R. F. Woron, S. M. Zansky, G. Dowdle, F. Smith, S. Ahrabi-Fard, A. R. Ong, N. Tucker, N. A. Hynes, and P. Mead. 2005. "Multistate Outbreak of Listeria 
monocytogenes Infection Link to Delicatessen Turkey Meat." Clinical Infectious Diseases 40 (7): 962-967.

Ramaswamy, V., V. M. Cresence, J. S. Rejitha, M. U.

Lekshmi, K. S. Dharsana, S. P. Prasad, and H. M. Vijila.

2007. "Listeria: Review of Epidemiology and Pathogenesis." Journal of Microbiology, Immunology, and Infection 40:

4-13.

Scallan, E., R. M. Hoekstra, F. J. Angulo, R. V. Tauxe, M. A. Widdowson, S. L. Roy, J. L. Jones, and P. M. Griffin. 2011. "Foodborne Illness Acquired in the United States - Major Pathogens." Emerging Infectious Diseases 17 (1): 7-15. 